\section{Early-onset autoimmune disease due to a heterozygous loss-of-function mutation in TNFAIP3 (A20)}

Rare Mendelian disorders increasingly contribute to our understanding of the genetic architecture of autoimmune disease and the key molecular pathways governing its pathogenesis. Earlyonset autoimmune disease can arise through activating mutations in inflammatory signalling pathways or loss-of-function mutations in immunoregulatory proteins.

We investigated the molecular basis of complex autoimmunity-characterised by the onset of insulin-dependent diabetes, cytopaenias, hepatitis, enteropathy and interstitial lung disease at age 10 -in a 14-year-old boy of healthy non-consanguineous British parents. Immunological analysis revealed lymphopaenia with no naive $\mathrm{T}$ cells and a high proportion of activated $\mathrm{T}$ cells (table 1). Pathogenic variants in STAT3 and FOXP3 were excluded. The clinical course was refractory to intensive immunosuppression with prednisolone, sirolimus, tacrolimus, infliximab or rituximab, necessitating haematopoietic stem cell transplantation. Twenty-one months post-transplant, he is thriving off all immunosuppressive medication with complete remission of autoimmune disease (except diabetes).

Ethical approval was granted (ref: 10/H0906/22) and written informed consent provided prior to study commencement. By whole exome sequencing of peripheral blood genomic DNA (Illumina MiSeq) and downstream bioinformatic filtering (Ingenuity Variant Analysis), we identified a single biologically plausible variant-a novel de novo heterozygous 2 bp deletion in tumour necrosis factor-alpha-induced protein 3 (TNFAIP3, figure 1A). TNFAIP3 encodes the ubiquitin-editing enzyme A20, a negative regulator of the nuclear factor- $\kappa \mathrm{B}(\mathrm{NF}-\kappa \mathrm{B})$ pathway. ${ }^{1}$ A20 removes K63-linked ubiquitin chains from key adaptor proteins, replacing them with K48-linked polyubiquitin chains, to trigger proteasomal degradation and termination of the NF- $\kappa \mathrm{B}$ activation cascade. ${ }^{2}$ Polymorphisms in TNFAIP3 have been linked to the development of several autoimmune diseases in genome-wide association studies. ${ }^{3-7}$ A conditional knockout of A20 in immune cells leads to the development of autoimmunity in the mouse. ${ }^{8}$ However, autoimmune phenomena were not prominent in a recently described cohort of patients with 


\begin{tabular}{|c|c|c|c|}
\hline Parameters & Pretransplant & $\begin{array}{l}\text { Post- } \\
\text { transplant }\end{array}$ & $\begin{array}{l}\text { Reference } \\
\text { range }\end{array}$ \\
\hline \multicolumn{4}{|l|}{ Laboratory } \\
\hline Haemoglobin (g/dL) & 9.8 & 12.4 & $13.5-17.5$ \\
\hline Leucocytes $\left(10^{9} / \mathrm{L}\right)$ & 1.88 & 3.47 & $150-450$ \\
\hline Lymphocytes $\left(10^{9} / \mathrm{L}\right)$ & 0.17 & 1.31 & $1.2-5.2$ \\
\hline Neutrophils $\left(10^{9} / \mathrm{L}\right)$ & $1.52^{*}$ & 1.79 & $1.8-8.0$ \\
\hline Monocytes $\left(10^{9} / L\right)$ & 0.19 & 0.37 & $0.2-0.8$ \\
\hline Platelets $\left(10^{9} / \mathrm{L}\right)$ & 29 & 183 & $150-400$ \\
\hline 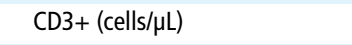 & 800 & 1914 & $800-3500$ \\
\hline CD8+ (cells/ $\mu \mathrm{L})$ & 554 & 936 & $200-1200$ \\
\hline CD4+ (cells/ $\mu \mathrm{L})$ & 238 & 920 & $400-1200$ \\
\hline CD56+ (cells/ $\mu \mathrm{L})$ & 35 & 99 & $70-1200$ \\
\hline CD19+ (cells/ $\mu \mathrm{L})$ & 138 & 99 & $200-600$ \\
\hline $\begin{array}{l}\text { Activated T cells } \\
\text { (HLA-DR+ \%) }\end{array}$ & 55 & 25 & N/A \\
\hline CD4+ naive (\%) & Not detected & 244 & $\mathrm{~N} / \mathrm{A}$ \\
\hline CD27- IgD+ (naive) (\%) & 87 & 93 & $75.2-86.7$ \\
\hline $\mathrm{CD} 27+\lg \mathrm{D}+$ (memory) $(\%)$ & 9 & 4 & $4.6-10.2$ \\
\hline $\begin{array}{l}\text { CD27+ IgD- } \\
\text { (class-switched) (\%) }\end{array}$ & 2 & 3 & $3.3-9.6$ \\
\hline $\lg M(g / L)$ & 0.55 & 0.25 & $0.50-1.90$ \\
\hline $\lg G(g / L)$ & 6.4 & 8.2 & $5.4-16.1$ \\
\hline $\lg A(g / L)$ & 0.92 & 0.33 & $0.80-2.80$ \\
\hline Tetanus (IU/mL) & 0.93 & ND & $0.1-10$ \\
\hline $\begin{array}{l}\text { Haemophilus influenzae b (mg/ } \\
\mathrm{mL})\end{array}$ & 1.8 & ND & $1.0-20.0$ \\
\hline Pneumococcal (mg/mL) & 10 & ND & $20-200$ \\
\hline Anti-GAD antibody (IU/mL) & $>2000$ & $>2000$ & $0-9.9$ \\
\hline Islet cell antibody & Detected & Detected & $\mathrm{N} / \mathrm{A}$ \\
\hline pANCA & Detected & Detected & $\mathrm{N} / \mathrm{A}$ \\
\hline \multicolumn{4}{|l|}{ Clinical } \\
\hline $\mathrm{FEV}_{1}(\%$ predicted $)$ & 38 & 84 & $95-100$ \\
\hline
\end{tabular}

*Peripheral neutrophils were supported pretransplant by recombinant granulocyte colony stimulating factor. Post-transplant parameters were obtained at 18 months (FBC and T-cell indices, lung function) or 21 months post-HSCT (B cell and antibody indices). Post-HSCT antibody indices were measured during concomitant subcutaneous immunoglobulin supplementation. No other autoantibodies were detected pre-HSCT or post-HSCT.

$F B C$, full blood count; $F E V_{1}$, forced expiratory volume in $1 \mathrm{~s} ; \mathrm{GAD}$, glutamic acid decarboxylase; HLA-DR, human leucocyte antigen-antigen D related; HSCT, haematopoietic stem cell transplantation; ND, not done; PANCA, perinuclear anti neutrophil cytoplasmic antibody.

germline A20 haploinsufficiency, who instead presented with an autoinflammatory phenotype resembling Behçet's disease. ${ }^{9}$

The c.1466_1467delTG variant-which we confirmed by capillary sequencing ${ }^{10}$ (figure $1 \mathrm{~B}$ )—introduces a frameshift substitution of alanine for valine at position 489 , generating a downstream premature stop codon (p.V489Afs*7) in the zinc finger $(\mathrm{ZnF}) 2$ domain of A20. This variant is absent from public databases (ExAc/dbSNP) and distinct from disease-associated mutations affecting the ovarian tumour or $\mathrm{ZnF} 4$ domains of $\mathrm{A} 20^{9}$ (figure 1C). Immunoblotting ${ }^{10}$ of patient and control dermal fibroblast lysates with an $\mathrm{N}$-terminal antibody confirmed the reduced basal and TNF- $\alpha$-induced expression of A20 (figure 1D).

To address the consequence of this reduced A20 expression, we performed functional experiments in patient and control dermal fibroblasts. Initially, we stimulated these cells with TNF- $\alpha(10 \mathrm{ng} /$ $\mathrm{mL}$ ) and analysed downstream signalling events by immunoblot (figure 1E). We observed exaggerated and prolonged phosphorylation of components of the NF- $\kappa B$ pathway, which would be expected to enhance NF- $\mathrm{kB}$-dependent transcriptional effects. In keeping with this prediction, RNA sequencing (Illumina NextSeq-500) revealed a significant global increase in both the range and magnitude of TNF- $\alpha$-stimulated differential gene expression (fold-change $\geq 2$; false discovery rate-adjusted $\mathrm{p} \leq 0.01$, figure $1 \mathrm{~F})$. We also confirmed enhanced expression of the key NF- $\mathrm{KB}$ target gene interleukin 6 (IL-6) at the protein level by ELISA $(p=0.0015$, figure $1 G)$. In these respects, the molecular consequences of the p.V489Afs*7 variant were indistinguishable from reported pathogenic A20 mutations, ${ }^{9}$ although owing to the lack of leucocyte material, we were not able to extend our analysis to inflammasome activation.

Here we provide novel validation of considerable existing evidence that implicates TNFAIP3 in autoimmune pathogenesis. This case expands the clinical spectrum of A20 haploinsufficiency. ${ }^{9}$ As A20 regulates multiple innate and adaptive signalling pathways, ${ }^{1}$ it is logical that patients with inactivating mutations in A20 might manifest pathological features of autoimmunity and/or autoinflammation. Finally, we report that correction of the molecular defect within the haematopoietic cell compartment could represent a viable treatment option for severe clinical manifestations.

Christopher J A Duncan, ${ }^{1}$ Emma Dinnigan, ${ }^{1}$ Rachel Theobald, ${ }^{1}$ Angela Grainger, ${ }^{1}$ Andrew J Skelton, ${ }^{2}$ Rafiqul Hussain, ${ }^{3}$ Joseph D P Willet, David J Swan, ${ }^{1}$ Jonathan Coxhead, ${ }^{3}$ Matthew F Thomas, ${ }^{4}$ Julian Thomas, ${ }^{5}$ Veena Zamvar, ${ }^{6}$ Mary A Slatter, ${ }^{7}$ Andrew J Cant, ${ }^{7}$ Karin R Engelhardt, ${ }^{1}$ Sophie Hambleton ${ }^{1,}$

${ }^{1}$ Primary Immunodeficiency Group, Institute for Cellular Medicine, Newcastle University, UK

${ }^{2}$ Bioinformatics Support Unit, Institute for Cellular Medicine, Newcastle University, UK

${ }^{3}$ Genomic Core Facility, Institute for Genetic Medicine, Newcastle University, UK ${ }^{4}$ Department of Paediatric Respiratory Medicine, Great North Children's Hospital, Royal Victoria Infirmary, UK

${ }^{5}$ Department of Paediatric Gastroenterology, Great North Children's Hospital, Royal Victoria Infirmary, UK

${ }^{6}$ Department of Paediatric Gastroenterology, Leeds General Infirmary, UK ${ }^{7}$ Department of Paediatric Immunology and Stem Cell Transplant Unit, Great North Children's Hospital, Newcastle upon Tyne Hospitals NHS Foundation Trust, UK

Correspondence to Prof Sophie Hambleton, Primary Immunodeficiency Group, Institute for Cellular Medicine, Newcastle University Medical School, Newcastle upon Tyne NE2 4HH, UK; sophie.hambleton@ncl.ac.uk

Acknowledgements The authors thank the patient and their family for their trust and assistance. They are grateful to colleagues in St. James' Hospital, Leeds and Great North Children's Hospital, Newcastle for providing clinical care. They thank R. Harry, N. Maney, J. Isaacs and A. Pratt for the kind gift of reagents.

Contributors CJAD, KRE and SH: designed research. MFT, JT, VZ, MAS, AJC and SH: clinical investigation and phenotyping. CJAD, ED, RT, AG, JDPW and DJS: performed experiments. CJAD, ED, RT, AJS, KRE and SH: analysed and interpreted data. CJAD and AJS: performed statistical analysis; CJAD and SH: wrote the manuscript. All authors: reviewed the manuscript for intellectual content.

Funding CJAD was supported by the Academy of Medical Sciences (AMS-SGCL11), the British Infection Association and the UK National Institute for Health Research (NIHR); JDPW, DJS, KRE and SH were supported by the Sir Jules Thorn Trust (12/JTA); AG was supported by the Bubble Foundation; AJS was supported by the MRCArthritis Research UK Centre for Integrated research into Musculoskeletal Ageing (CIMA) and NIHR Newcastle Biomedical Research Centre.

Competing interests None declared.

Patient consent Obtained.

Ethics approval NHS North East-Newcastle and North Tyneside 1 REC.

Provenance and peer review Not commissioned; externally peer reviewed.

Data sharing statement RNA-Seq data have been submitted to GEO (ref: GSE95078). Details of Sanger sequencing primers and the Ingenuity Variant Analysis bioinformatic filtering strategy are available on request. 

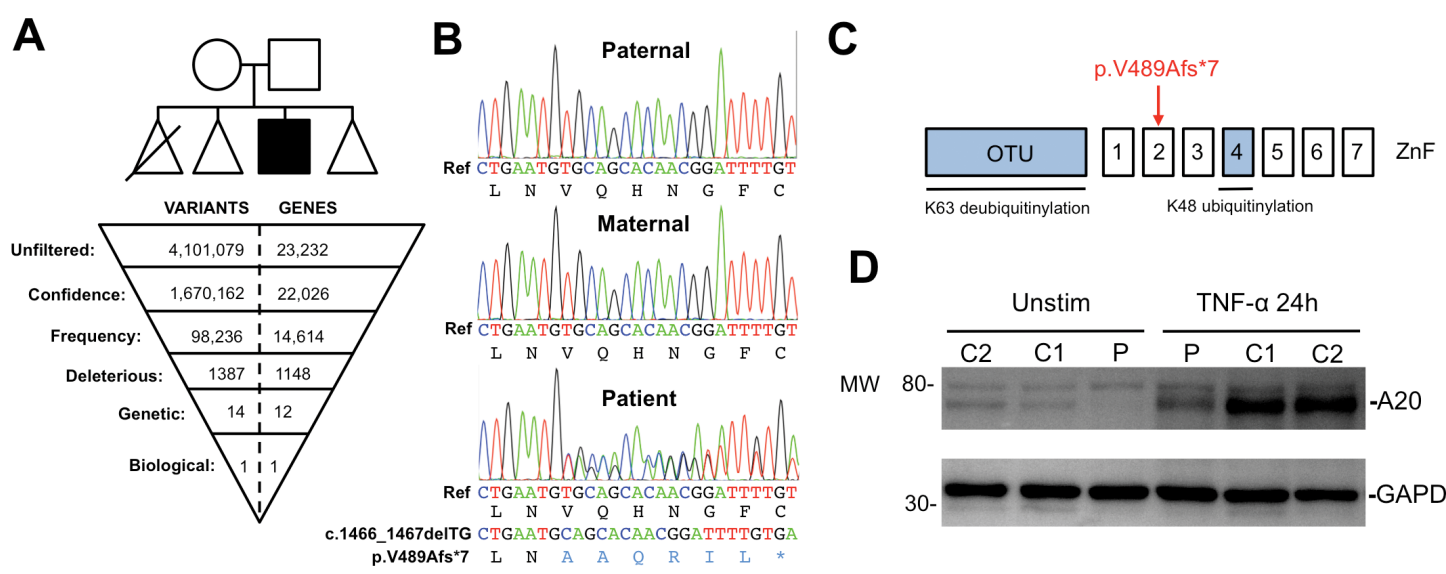

D
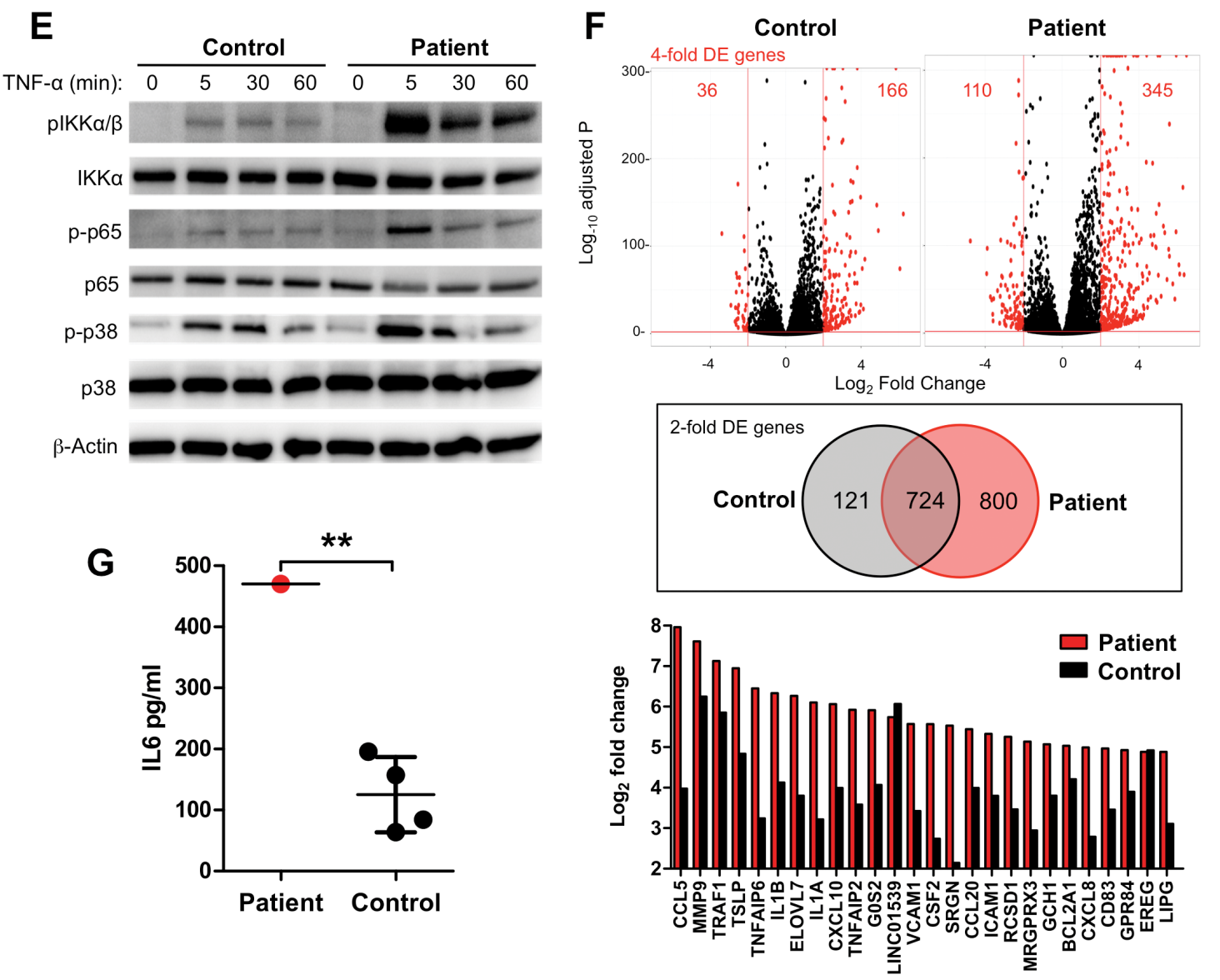

Figure 1 TNFAIP3 variant identification and functional validation. (A) The family pedigree is shown (triangles are used to preserve the anonymity of healthy unaffected siblings). The first-born infant died as a result of prematurity. Whole exome sequencing data were filtered (Ingenuity Variant Analysis) by confidence (call quality $\geq 20$; read depth $\geq 10$; allele fraction $\geq 45 \%$ ); frequency (ExAc allele frequency $\leq 0.01 \%$ ); deleteriousness (nonsense/deleterious missense (SIFT/PolyPhen), splice-site disruption); genetic segregation (ie, present in patient and absent from 47 unrelated disease controls) and biological function (linked to phenotype), identifying a single heterozygous frameshift variant in TNFAIP3 (c.1466_1467TGdel). (B) Variant confirmation by Sanger sequencing. (C) The c.1466_1467TGdel variant resulted in a frameshift and premature stop codon (V489Afs*7) in the second ZnF domain and is distinct from previously described mutations in the OTU and ZnF4 domains (blue). (D) V489Afs*7 reduced basal and TNF-induced A20 protein in patient (P) versus control $(C 1, C 2)$ fibroblasts (immunoblot representative of $n=4$ independent experiments with $\mathrm{n}=4$ controls). (E) Signalling responses downstream of TNF- $\alpha$ stimulation in patient fibroblasts were exaggerated and prolonged compared with control (immunoblot representative of $n=4$ independent experiments with $n=4$ controls). (F) RNA-seq analysis of transcriptional response to 6 -hour TNF- $\alpha$ stimulation in patient and control fibroblasts (stimulations performed in triplicate in a single experiment). Top panel: displayed in red are significant (FDR-corrected $p \leq 0.01$ ) DE transcripts regulated $\geq 4$ fold ( $\geq 2 \log _{2}$-fold); middle panel: Venn diagram displaying all overlapping DE transcripts $\geq 2$ fold ( $\geq \log _{2}$-fold); Bottom panel: top 20 significant DE transcripts in patient (red bars) versus control (black bars), demonstrating many major NF-KB target genes. (G) Levels of IL-6 quantified by ELISA in supernatants from patient and control fibroblasts stimulated with $\mathrm{TNF}-\alpha$ for 24 hours (mean \pm SD of average values from two independent experiments in patient and $\mathrm{n}=4$ controls compared by one-sample t-test; $\left.{ }^{* *} \mathrm{p}=0.0015\right)$. $\mathrm{DE}$, differentially expressed; FDR, false discovery rate; IL-6, interleukin 6; NF- $\mathrm{KB}$, nuclear factor- $\mathrm{KB} ; \mathrm{OTU}$, ovarian tumour; PolyPhen, polymorphism phenotyping; SIFT, Sorting Intolerant from Tolerant; TNF- $\alpha$, tumour necrosis factor-alpha; TNFAIP3, tumour necrosis factor-alphainduced protein 3; ZnF, zinc finger. 


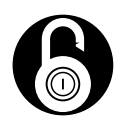

\section{OPEN ACCESS}

Open Access This is an Open Access article distributed in accordance with the terms of the Creative Commons Attribution (CC BY 4.0) license, which permits others to distribute, remix, adapt and build upon this work, for commercial use, provided the original work is properly cited. See: http://creativecommons.org/licenses/by/4.0/

(c) Article author(s) (or their employer(s) unless otherwise stated in the text of the article) 2018. All rights reserved. No commercial use is permitted unless otherwise expressly granted.

CJAD, ED and RT contributed equally.

\section{D) Check for updates}

To cite Duncan CJA, Dinnigan E, Theobald R, et al. Ann Rheum Dis 2018;77:783-786

Received 3 January 2017

Revised 24 April 2017

Accepted 18 May 2017

Published Online First 28 June 2017

Ann Rheum Dis 2018;77:783-786. doi:10.1136/annrheumdis-2016-210944

\section{REFERENCES}

1 Catrysse L, Vereecke L, Beyaert R, et al. A20 in inflammation and autoimmunity. Trends Immunol 2014:35:22-31.

2 Wertz IE, Newton K, Seshasayee D, et al. Phosphorylation and linear ubiquitin direct A20 inhibition of inflammation. Nature 2015;528:370-5.

3 Graham RR, Cotsapas C, Davies L, et al. Genetic variants near TNFAIP3 on $6 \mathrm{q} 23$ are associated with systemic lupus erythematosus. Nat Genet 2008;40:1059-61.

4 Musone SL, Taylor KE, Lu TT, Tt L, et al. Multiple polymorphisms in the TNFAIP3 region are independently associated with systemic lupus erythematosus. Nat Genet 2008;40:1062-4.

5 Fung EY, Smyth DJ, Howson JM, et al. Analysis of 17 autoimmune disease-associated variants in type 1 diabetes identifies 6q23/TNFAIP3 as a susceptibility locus. Genes Immun 2009:10:188-91.

6 Lodolce JP, Kolodziej LE, Rhee L, et al. African-derived genetic polymorphisms in TNFAIP3 mediate risk for autoimmunity. J Immunol 2010;184:7001-9.

7 Musone SL, Taylor KE, Nititham J, et al. Sequencing of TNFAIP3 and association of variants with multiple autoimmune diseases. Genes Immun 2011:12: $176-82$.

8 Tavares $\mathrm{RM}$, Turer $\mathrm{EE}$, Liu $\mathrm{CL}$, et al. The ubiquitin modifying enzyme A20 restricts B cell survival and prevents autoimmunity. Immunity 2010;33:181-91.

9 Zhou Q, Wang H, Schwartz DM, et al. Loss-of-function mutations in TNFAIP3 leading to A20 haploinsufficiency cause an early-onset autoinflammatory disease. Nat Genet 2016:48:67-73.

10 Duncan CJ, Mohamad SM, Young DF, et al. Human IFNAR2 deficiency: Lessons for antiviral immunity. Sci Trans/ Med 2015;7:307ra154. 